Article

\title{
Control of Growth and Persistence of Listeria monocytogenes and $\beta$-Lactam-Resistant Escherichia coli by Thymol in Food Processing Settings
}

\author{
Maria Grazia Cusimano ${ }^{1}$, Vita Di Stefano ${ }^{1}{ }^{\mathbb{C}}$, Maria La Giglia ${ }^{2}$, Vincenzo Di Marco Lo Presti ${ }^{2}$, \\ Domenico Schillaci $^{1, *(\mathbb{D})}$, Francesco Pomilio ${ }^{3}$ and Maria Vitale ${ }^{2}$ (D) \\ 1 Department of Biological, Chemical and Pharmaceutical Sciences and Technologies (STEBICEF), \\ via Archirafi 32, 90123 Palermo, Italy; mariagrazia.cusimano@unipa.it (M.G.C.); \\ vita.distefano@unipa.it (V.D.S.) \\ 2 IZS Istituto Zooprofilattico Sperimentale della Sicilia via Gino Marinuzzi, 3, 90129 Palermo, Italy; \\ maria.lagiglia8@gmail.com (M.L.G.); dimarco.vince@gmail.com (V.D.M.L.P.); maria.vitale@izssicilia.it (M.V.) \\ 3 Centro di Referenza Nazionale Listeria at Istituto Zooprofilattico Sperimentale Abruzzo Molise, \\ via Campo Boario, 64100 Teramo, Italy; f.pomilio@izs.it \\ * Correspondence: domenico.schillaci@unipa.it
}

Received: 6 November 2019; Accepted: 14 January 2020; Published: 17 January 2020

\begin{abstract}
The main objective of this study was to evaluate the efficacy of thymol in controlling environmental contamination in food processing facilities. The effect of thymol was tested as an agent to prevent planktonic and bacterial biofilm growth of twenty-five Listeria monocytogenes isolates from a variety of foods and five Escherichia coli isolates from a farm. The E. coli isolates were positive for extended spectrum $\beta$-lactamase (ESBL) genes. All isolates and reference strains were susceptible to thymol at Minimum inhibitory concentration (MIC) values ranging from 250 to $800 \mu \mathrm{g} / \mathrm{mL}$. An interesting activity of interference with biofilm formation of L. monocytogenes and E. coli was found for thymol at sub-MIC concentrations of 200, 100, 75, and $50 \mu \mathrm{g} / \mathrm{mL}$. Anti-biofilm activity ranging from $59.71 \%$ to $66.90 \%$ against pre-formed 24 -h-old L. monocytogenes biofilms at concentrations of 500 or $800 \mu \mathrm{g} / \mathrm{mL}$, corresponding to $2 \times$ MIC, was determined against free-living forms of six isolates chosen as the best or moderate biofilm producers among the tested strains. The property of thymol to attack L. monocytogenes biofilm formation was also observed at a concentration of $100 \mu \mathrm{g} / \mathrm{mL}$, corresponding to $1 / 4 \mathrm{MIC}$, by using a stainless-steel model to simulate the surfaces in food industries. This study gives information on the use of thymol in food processing setting.
\end{abstract}

Keywords: biofilm; ESBL; Escherichia coli; Listeria monocytogenes; thymol

\section{Introduction}

Each year, millions of people get infected and die from antibiotic-resistant pathogens [1]. Antimicrobial resistance (AMR) is a serious concern for public health and its spread has increased over time due to the excessive use of similar antibiotic molecules in both human and animal health. Modern industrial agriculture is based on the extensive use of antimicrobials as therapeutics and prophylactics, particularly in intensively farmed species, such as pigs and poultry [2]. AMR renders ineffective the control of diseases caused by pathogenic bacteria that are mostly common between humans and animals [3]. It is necessary to reduce the use of antibiotics or replace them with new treatments in farms, food processing facilities, and other non-clinical settings to avoid the loss of efficacy of critically or highly important antibiotics used in clinical treatment, such as fluoroquinolones, aminoglycosides, and third- and fourth-generation cephalosporins [4]. 
With the aim to find alternative strategies to the use of conventional antibiotics and disinfectants on farms and industrial settings, to decrease the impact of antibiotic resistance, and to preserve the efficacy of conventional antibiotics, we focused on thymol, one of the most common terpenes found in many essential oils from a number of plants, including oregano, thymus, and myrtle. Thymol has been reported to have a wide spectrum of biological actions, such as antiseptic, antibacterial, antifungal, and anti-inflammatory activities. Currently, it is used mainly as an antiseptic, a fungicide, and a preservative and is a known ingredient in numerous complex natural antiseptic products [5]. In addition, thymol is approved by the US Food and Drug Administration (FDA) as a flavoring agent or an adjuvant and is a generally recognized as safe (GRAS) substance (https://www.accessdata.fda.gov/scripts/fdcc/ ?set=FoodSubstances), so it has good potential in the development of useful and sustainable alternative strategies to control pathogens in food processing settings and livestock. Moreover, the adhesion of bacteria and biofilm formation on working surfaces and food products are undesirable and harmful for the food industry and it can lead to serious health problems related to antibiotic-resistant foodborne pathogens [6]. Floors, walls, cooling pipes, freezers, packaging materials, and gloves are common sites for biofilm formation [7]. The ability to form biofilms is frequent among major foodborne pathogens, such as Escherichia coli, Salmonella spp., and Listeria monocytogenes [8] and biofilms remain a significant safety challenge in the food industry [9].

In recent years, many natural antimicrobials derived from plants, such as trans-cinnamaldehyde, carvacrol, eugenol, and thymol, have been tested. Interestingly, not all the tested substances with antimicrobial properties were proven to be effective against biofilms. On the contrary, some compounds ( $\alpha$-pinene, 1,8-cineole, (+)limonene, linalool, and geranyl acetate) enhanced biofilm growth in vitro [10]. Essential oil components from orange peels [11] and a lot of other substances, including epicatechin, $\beta$-sitosterol, and epigallocatechin from Acacia karroo [12] and resveratrol [13], were evaluated successfully. Thymol has been also screened as an alternative to conventional antibiotics to inhibit biofilm formation and it was found to be effective against biofilms formed by Staphylococcus aureus and Staphylococcus epidermidis [14]. The activity of thymol has also been frequently evaluated against biofilms formed by the fungal pathogen, Candida albicans [15].

In this study, thymol was assessed as an agent to prevent planktonic and bacterial biofilm growth of L. monocytogenes, which is a major cause of foodborne disease [16] and E. coli, which is mainly a commensal microorganism, but many pathogenic strains have been detected in humans and animals [17]. In particular, twenty-five L. monocytogenes isolates from a variety of food samples and five reference strains were analyzed. The interference of thymol with the growth of L. monocytogenes has been recognized for a long time [18-20], but as far as we know, it is the first time that a good number of food isolates were tested for susceptibility to thymol. The aim of the study was to suggest and support the replacement or reduction of the use of antibiotics in food processing settings and in farms.

\section{Results and Discussion}

For this study, we selected E. coli isolates from a swine farm with diarrhea episodes in piglets. The isolates were genetically analyzed to evaluate their virulent and pathogenic genes and extended spectrum $\beta$-lactamase (ESBL) genes. All isolates belonged to the $\mathrm{O} 103$ serotype and carried a hemolysin gene $(e h x A)$. Four isolates carried TEM as the ESBL gene and three isolates carried the dispersin transporter gene (aat $A)$. The aat $A$ gene is a key gene in enteroaggregative $E$. coli (EAEC) and it encodes part of the outer membrane transport system (ABC transporter) involved in the translocation of the dispersin protein. The aat $A$ and ast $A$ genes are associated with prolonged diarrhea in EAEC strains [21]. Three different phylogenetic groups were detected, although all isolates came from the same farm. Two isolates belonged to the phylogenetic group $C$, which is mainly associated with virulent strains in contrast to groups A and B, which are associated with commensal strains [22].

An MIC analysis of thymol was performed against planktonic forms of all five E. coli isolates. Thymol was active at concentrations of $400 \mu \mathrm{g} / \mathrm{mL}$ against four of the field isolates (4/5) and on the 
reference E. coli strains, ATCC 25922, ATCC 10536, and ATCC 8739. For the isolate E. coli 335, an MIC value of $300 \mu \mathrm{g} / \mathrm{mL}$ was detected.

The analysis on biofilm capability showed that, among the $E$. coli isolates, the best biofilm producer in microtiter plate assay at $37^{\circ} \mathrm{C}$ was E. coli 336. This strain showed an optical density (OD) value of 0.319 at $600 \mathrm{~nm}$, in contrast to the other strains that showed OD values around 0.130. We do not know why the $E$. coli strain lacking the aat $A$ gene was so strong in the in vitro test, despite the association of dispersin transporter with biofilm formation. To analyze the anti-biofilm activity of thymol in E. coli, the experiments were run only against $E$. coli 336 . Table 1 reports data concerning the genetic analysis, biofilm formation, and MIC values of thymol against planktonic forms of the field strains. 
Table 1. Genetic analysis on Escherichia coli isolates, biofilm formation, and thymol MIC data.

\begin{tabular}{|c|c|c|c|c|c|c|c|c|c|c|c|c|c|c|c|c|}
\hline & & & & & & & & & & aatA & $\operatorname{shf}$ & Irp2 & $w z x 0103$ & $e h x A$ & & Thymol \\
\hline $\begin{array}{l}\text { E. coli } \\
\text { Isolate }\end{array}$ & $\begin{array}{l}\text { Phylogenetic } \\
\text { Group }\end{array}$ & $T E M$ & $\begin{array}{l}C T X \\
M I V\end{array}$ & OXA & SHV & $\begin{array}{l}C T X \\
M I\end{array}$ & CMYII & $\begin{array}{l}\text { CTX } \\
\text { MII }\end{array}$ & DHA & $\begin{array}{l}\text { Dispersin } \\
\text { Transporter }\end{array}$ & $\begin{array}{l}\text { Cryptic Open } \\
\text { Reading }\end{array}$ & $\begin{array}{l}\text { Yersinia } \\
\text { Bactin }\end{array}$ & $\begin{array}{l}\text { O-polysaccharide } \\
\text { Export }\end{array}$ & $\begin{array}{l}\text { Virulence } \\
\text { Gene }\end{array}$ & $\begin{array}{l}\text { Biofilm } \\
\text { Formation }\end{array}$ & $\begin{array}{c}\text { MICs } \\
(\mu \mathrm{g} / \mathrm{mL})\end{array}$ \\
\hline 334 & A & + & - & - & - & - & - & - & - & - & - & - & + & + & - & 400 \\
\hline 335 & B1 & + & - & - & - & - & - & - & - & + & - & - & + & + & - & 300 \\
\hline 336 & B1 & + & - & - & - & - & - & - & - & - & - & - & + & + & + & 400 \\
\hline 337 & C & + & - & - & - & - & - & - & - & + & - & - & + & + & - & 400 \\
\hline 339 & C & + & - & - & - & - & - & - & - & + & - & - & + & + & - & 400 \\
\hline
\end{tabular}


The results of thymol inhibition on the formation of new biofilms by the best biofilm producer E. coli 336 are presented in Table 2.

Table 2. Inhibition of E. coli 336 biofilm formation at sub-MIC concentrations of thymol. The averages from three independent experiments are reported with the SD values.

\begin{tabular}{ccccc}
\hline \multicolumn{5}{c}{ Percentage Inhibition Biofilm Formation } \\
\hline Thymol & $200 \mu \mathrm{g} / \mathrm{mL}$ & $100 \mu \mathrm{g} / \mathrm{mL}$ & $75 \mu \mathrm{g} / \mathrm{mL}$ & $50 \mu \mathrm{g} / \mathrm{mL}$ \\
Inhibition $\%$ & $94 \% \pm 4.0 \%$ & $59.4 \% \pm 1.6 \%$ & $55 \% \pm 1.0 \%$ & $54.5 \% \pm 3.5 \%$ \\
\hline
\end{tabular}

Biofilm formation by the tested strain was almost completely inhibited (94\%) at a concentration of $200 \mu \mathrm{g} / \mathrm{mL}$ of thymol (1/2 MIC value), while it was inhibited from $59 \%$ to $54 \%$ at lower concentrations up to $50 \mu \mathrm{g} / \mathrm{mL}$ (1/8 MIC value). Unfortunately, no activity of thymol against pre-formed 24-h-old biofilm of E. coli 336 was detected. The inhibition of biofilm formation at much lower concentrations compared to MICs looks promising for further studies on the anti-biofilm properties of thymol against Gram-negative bacteria.

In L. monocytogenes isolates, the ability to produce biofilms ranged from 0.888 OD for the strain L. monocytogenes 101 (gene-serotype II), isolated from fish products, to 0.148 for the strain L. monocytogenes 48 (gene-serotype II), isolated from vegetable food products. The ODs of the sessile community of most of the isolates ranged from 0.461 to 0.290 and few weak producers showed ODs around 0.225. In our study, L. monocytogenes isolates of different origins and serotypes differed in the strength of biofilm formation and they can be divided based on their OD values into weak $(\mathrm{OD}=0.148-0.348)$, moderate $(\mathrm{OD}=0.370-0.542)$, and strong biofilm producers ( $\mathrm{OD}=0.553-0.888)$. We observed that there was no relation between gene-serotype and the ability to form a biofilm in the described experimental conditions. The best reference L. monocytogenes strain was LM ATCC 19114 with an OD of 0.543. The values of OD for all isolates and reference strains are reported in Table 3. Thymol was active against all planktonic forms of the tested isolates and reference strains of L. monocytogenes at concentrations ranging from 250 to $800 \mu \mathrm{g} / \mathrm{mL}$. Ethanol, used to dissolve thymol, was not active against all the tested strains at $1 \% v / v$ (corresponding to the maximum volume of ethanol used at the maximum tested thymol concentration of $800 \mu \mathrm{g} / \mathrm{mL}$ ). The MIC values against the planktonic form of L. monocytogenes and reference strains are also reported in Table 3.

To evaluate the anti-biofilm activity of thymol, we focused only on isolates from food and selected the three best biofilm producers (LM 89, LM 101, and LM 104) and three moderate producers (LM 102, LM 106, and LM 118). The results of inhibition of biofilm formation are presented in Figure 1. For each strain, the greatest inhibition was observed at the sub-MIC concentration of $200 \mu \mathrm{g} / \mathrm{mL}$ and the percentages of inhibition ranged from 30.78\% for LM 89 to $61.56 \%$ for LM 106. A good inhibitory activity was also observed at 100 and $75 \mu \mathrm{g} / \mathrm{mL}$ against LM 106 and LM 118. In some cases (at a thymol concentration of $50 \mu \mathrm{g} / \mathrm{mL}$ for LM 89, and 75 and $50 \mu \mathrm{g} / \mathrm{mL}$ for LM 101), inhibition was below 15\% and was not considered significant. 
Table 3. Evaluation of biofilm formation as the optical density (OD) of crystal violet-stained adherent biomass and thymol MIC values in $\mu \mathrm{g} / \mathrm{mL}$ against L. monocytogenes isolates and reference strains. The averages from three independent experiments are reported with the SD values. Different letters indicate statistical differences at $p<0.05$ among the L. monocytogenes isolates.

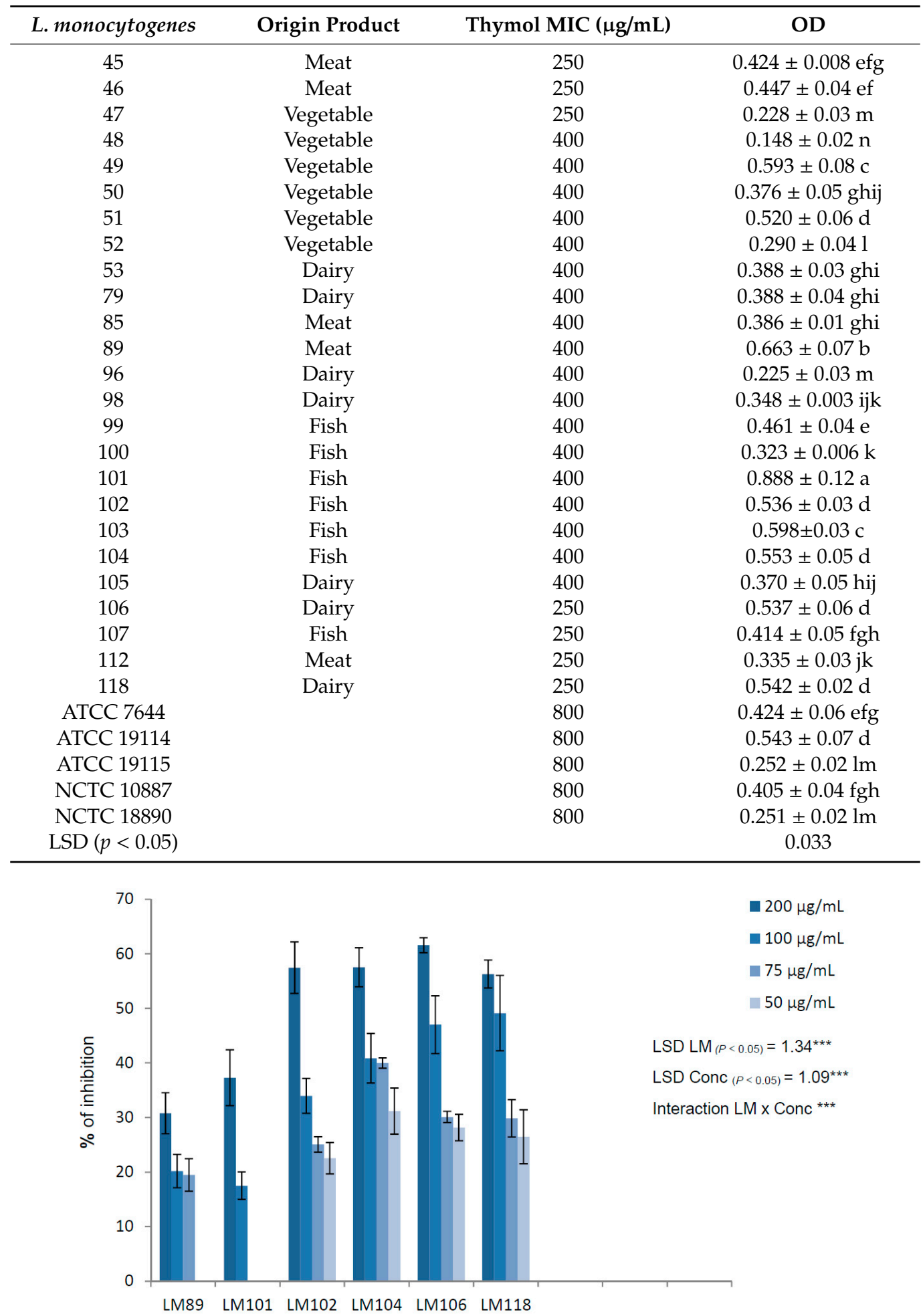

Figure 1. Percentages of inhibition of biofilm formation at sub-MIC concentrations of thymol against the best biofilm producers. The averages from three independent experiments are reported with the SD values. Error bars represent the SD of the data. LSD (least significant difference) was calculated at 0.05 probability level by the Student-Newman-Keuls (SNK) test [23]. 
The activity of thymol against mature biofilms (24-h old) of L. monocytogenes was evaluated at concentrations equal to MIC ( 250 or $400 \mu \mathrm{g} / \mathrm{mL}$ ) or $2 \times$ MIC (500 or $800 \mu \mathrm{g} / \mathrm{mL}$ ). The results are presented in Figure 2. At the concentration equal to the MIC value, the results against pre-formed biofilms were unevenly distributed for each isolate with values starting from 37.47\% for LM 101 to $61.59 \%$ for LM 102. At the concentration equal to $2 \times \mathrm{MIC}$, the anti-biofilm activity was higher and similar for each strain, ranging from $59.71 \%$ to $66.90 \%$.

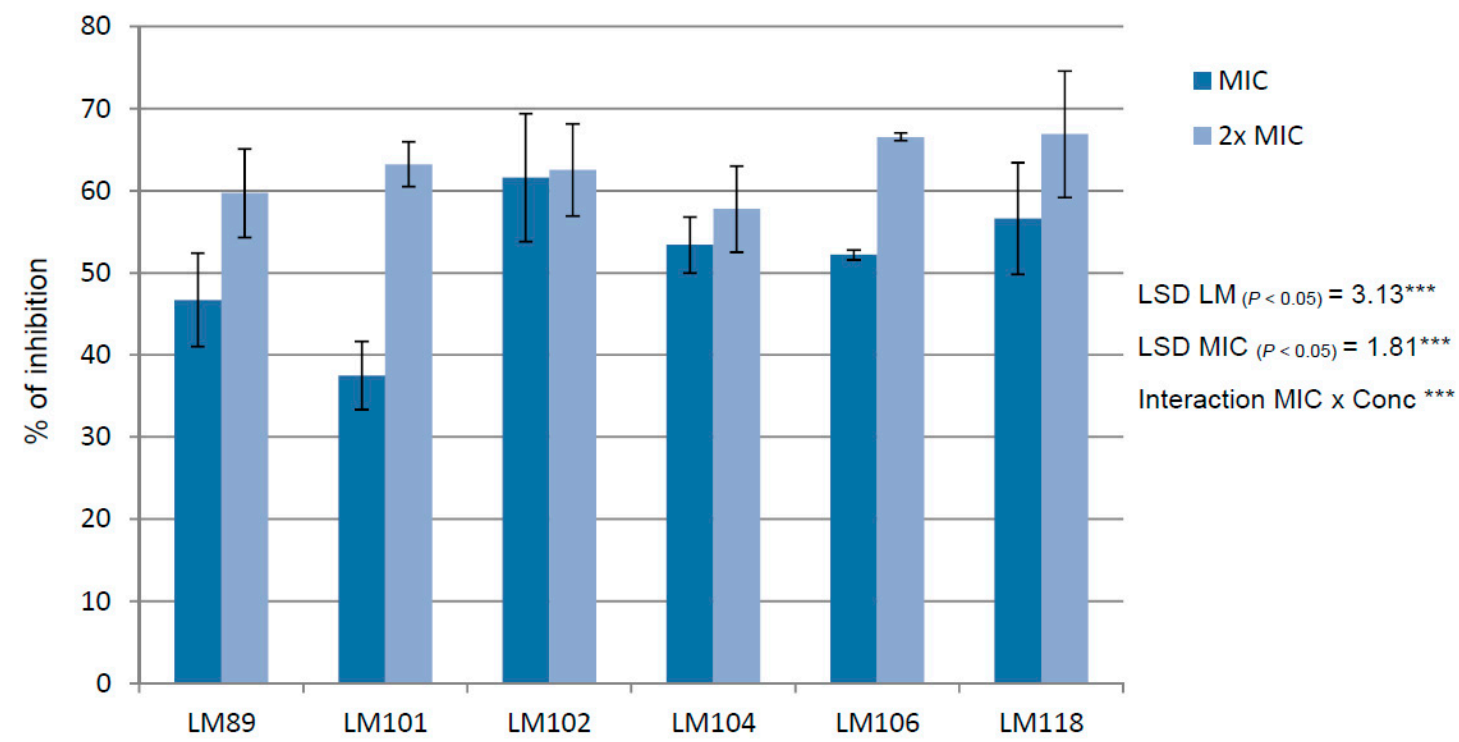

Figure 2. Activity against pre-formed 24-h-old biofilms at concentrations equal to MIC or $2 \times$ MIC. The averages from three independent experiments are reported with the SD values and error bars represent the SD of the data. LSD was calculated at 0.05 probability level by the SNK test [23].

The biofilm of L. monocytogenes 101 on a stainless-steel surface, used to simulate a common surface in food industries, was inhibited by thymol tested at a sub-MIC (1/4 MIC) concentration of $100 \mu \mathrm{g} / \mathrm{mL}$. Data are reported in Figure 3. The results are expressed in terms of log Colony Forming Unit/mL $(\mathrm{CFU} / \mathrm{mL})$ of viable count by comparing the growth in the presence of thymol with a non-treated control and another control treated with ethanol at the same concentration $(2 \% v / v)$ used to dissolve thymol. We observed a considerable log reduction (4.3) in the presence of thymol. Ethanol elicited a $\log$ reduction of 0.9 .

The search for alternative molecules to control bacterial infections and contamination is an important challenge worldwide, especially in the era of antimicrobial resistance. In this paper, we focused on two important bacterial species, a Gram-positive bacterium (L. monocytogenes) and a Gram-negative bacterium (E. coli), to test the antimicrobial activity of thymol in both the planktonic and sessile forms of these microorganisms. The analysis of the activity of thymol on the planktonic forms showed MIC values ranging from 250 to $400 \mu \mathrm{g} / \mathrm{mL}$ for the food isolates of L. monocytogenes and 300 to $400 \mu \mathrm{g} / \mathrm{mL}$ for the virulent and resistant $E$. coli isolates from the farm; however, lower concentrations are necessary to inhibit biofilm formation of both species and suggesting the possibility to develop molecules from thymol to inhibit both Gram-positive and Gram-negative bacteria. The inhibitory activity toward biofilm organization of both Gram-positive and Gram-negative bacteria could be very important in the sanitizing aspect to avoid persistent contamination. It is known that conventional sanitizers and detergents are more efficient against planktonic cells than against biofilms, and L. monocytogenes biofilm is still a challenge due to its extraordinary ability to survive in many drastic conditions [24]. The search for alternative methods to inhibit biofilm formation by L. monocytogenes is an important task to tackle the spread of antimicrobial resistance. We found that sub-MIC concentrations were able to inhibit biofilm formation on polystyrene microtiter plates at $37^{\circ} \mathrm{C}$. In some isolates (LM 102 and LM 104), inhibition was observed at levels as low as 1/8 MIC. Similar results were also observed with E. coli 336. 


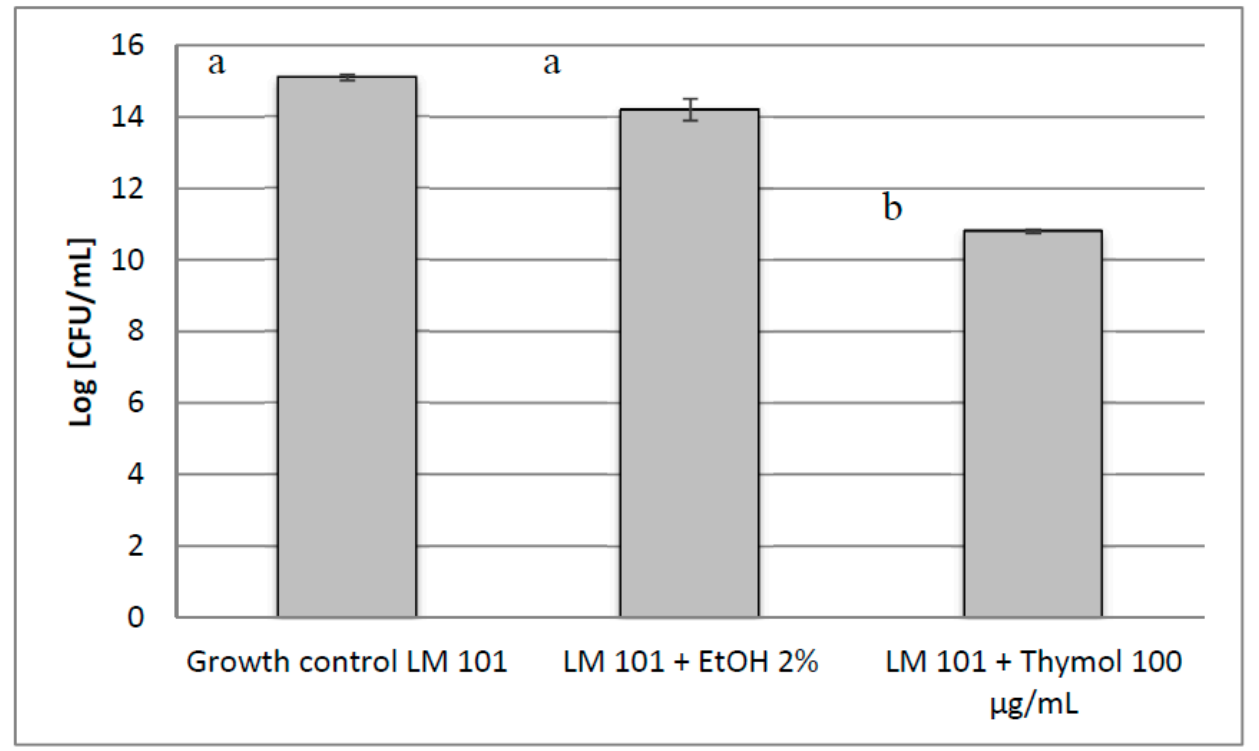

Figure 3. Inhibition of L. monocytogenes 101 (LM 101) biofilm formation on a stainless-steel surface. The averages from three independent experiments are reported with the SD values and error bars represent the SD of the data. Different letters among bars indicate statistical differences at $p<0.05$.

The anti-adhesion property of thymol could play an important role against foodborne pathogens, such as pathogenic E. coli and L. monocytogenes, suggesting and confirming that thymol could be used in the food industry as an environment-friendly antimicrobial agent to prevent or eradicate microbial biofilms $[25,26]$. The results of inhibition on the stainless-steel surface, simulating a food processing equipment, against the best biofilm producer L. monocytogenes (LM 101) further supported the potential use of thymol in sanitation procedures of food processing equipment.

Finally, the replacement or reduction of the use of conventional antimicrobials in food processing settings and in intensive farms by using a well characterized and sustainable molecule such as thymol can contribute to tackling the AMR phenomenon and to preserve antibiotics that should be reserved for human medicine.

\section{Materials and Methods}

\subsection{Bacterial Strains}

The following strains of L. monocytogenes were used: Twenty-five isolates from different foods (meat, fish, vegetable, and dairy products) and belonging to gene-serotype II or IV were supplied by the Italian Reference Laboratory (Teramo, Italy) for Listeria monocytogenes, Istituto Zooprofilattico Sperimentale of Abruzzo and Molise, Teramo, Italy. Five L. monocytogenes reference strains were also used (ATCC 7644, ATCC 19114, ATCC 19115, NCTC 10887, and NCTC 18890). Five E. coli strains (334, $335,336,337$, and 339) isolated from a swine farm with diarrhea episodes and supplied by Istituto Zooprofilattico Sperimentale of Sicilia, Palermo, Italy and three E. coli reference strains (ATCC 25922, ATCC 10536, and ATCC 8739) were also included in the analysis. The media used in this study were tryptic soy broth (TSB; Sigma-Aldrich, Milan, Italy) with $2 \%$ glucose and tryptic soy agar (TSA) without glucose. Thymol (purity $\geq 98.5 \%$ ) was purchased from Sigma-Aldrich, Milan, Italy.

\subsection{Genetic Analysis on E. coli Isolates}

The animal isolates of E. coli were analyzed through multiplex PCRs for the presence of extended spectrum $\beta$-lactamase (ESBL) and virulence factor genes as described in $[27,28]$.

The following multiplex PCRs were performed:

Two multiplex PCR assays (Set 1 and Set 2) for the genes of ESBL 
Set 1 for TEM, SHV, CTX M, and OXA genes;

Set 2 for CTX MI, CTX MII, CMYII, and DHA genes.

Two multiplex PCR assays (MPX1 and MPX2) for virulence factors and specific serogroups:

MPX1 for serogroups O45, O145, O26, and O157;

MPX2 for serogroups O103, O121, and O111.

A phylogroup analysis was performed as described in [29]. For the phylogroups A, B1, B2, and D,

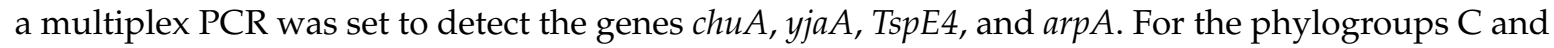

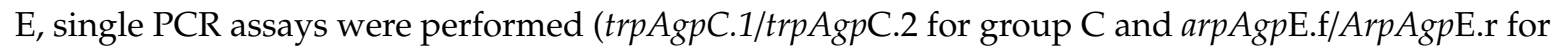
group E).

All PCR reactions were performed in $25 \mu \mathrm{L}$ final volume with 2 units of Taq Gold polymerase (Life Technologies, Monza, Italy). The results were visualized on $2 \%$ agarose gels with SYBR ${ }^{\circledR}$ Safe DNA gel stain under UV light.

\subsection{Determination of Minimal Inhibitory Concentrations (MICs)}

The MICs of thymol were determined by an agar dilution method using tryptic soy agar (TSA). A suitable volume of a solution of thymol in ethanol (ranging from 800 to $125 \mu \mathrm{g} / \mathrm{mL}$ ) was added to $20 \mathrm{~mL}$ of molten medium to obtain the required concentrations. The resulting mixture was poured onto Petri plates and allowed to solidify. Two plates were included as growth controls-one without the antimicrobial agent and the other with the maximum concentration of ethanol-to exclude the activity of ethanol at the highest concentration. The plates were inoculated with bacterial suspensions from a 24-h culture containing approximately $10^{6}$ colony forming units $/ \mathrm{mL}(\mathrm{CFU} / \mathrm{mL})$ of each strain and incubated at $37^{\circ} \mathrm{C}$ overnight. MICs of thymol were recorded as the lowest concentration of thymol that completely inhibited bacterial growth (absence of colonies). Ethanol, used to dissolve thymol, did not show any antibacterial activity at the concentration of $1 \% v / v$ used at the maximum tested thymol concentration of $800 \mu \mathrm{g} / \mathrm{mL}$. Two replicates were tested every time and the tests were repeated at least in three independent experiments. The MIC values obtained with the agar dilution method described above were also confirmed by a broth dilution micro-method using tryptic soy broth (TSB) in a 96-well plate [28].

\subsection{Evaluation of Biofilm Formation and Inhibition}

Test tubes filled with $5 \mathrm{~mL}$ TSB containing $2 \%$ glucose were inoculated with a loopful of a 24-h culture from TSA tubes and incubated at $37{ }^{\circ} \mathrm{C}$ for $24 \mathrm{~h}$. After the incubation time, $200 \mu \mathrm{L}$ of the medium (TSB with $2 \%$ glucose) and $2.5 \mu \mathrm{L}$ of bacterial suspension with an optical density (OD) of about 0.040 at $570 \mathrm{~nm}$, corresponding to approximately $10^{6} \mathrm{CFU} / \mathrm{mL}$, was added to each well. The microtiter plate was sealed with parafilm and incubated at $37^{\circ} \mathrm{C}$ for $24 \mathrm{~h}$. The wells were washed twice with $0.9 \%$ sterile $\mathrm{NaCl}$ and stained with $100 \mu \mathrm{L}$ of $0.1 \%$ crystal violet solution for $10 \mathrm{~min}$ at room temperature. The excess solution was removed and the plate was washed twice using tap water. To solubilize the dye, $200 \mu \mathrm{L}$ of ethanol was added to each stained well for $10 \mathrm{~min}$ at room temperature [30]. All tests involved six replicates and were repeated at least in three independent experiments. Optical density (OD) was read at a wavelength of $600 \mathrm{~nm}$ using a plate reader (GloMax ${ }^{\circledR}$-Multi Detection System, Promega Italia s.r.l, Milan, Italy). The calculation of mean and standard deviation (SD) was done on a PC with the computer program, Microsoft Excel 2010 (Microsoft Corporation, Redmond, WA, USA).

\subsection{Inhibition of Biofilm Formation}

L. monocytogenes or E. coli strains were incubated as described above. An aliquot of $2.5 \mu \mathrm{L}$ was added to each well of a polystyrene, sterile, flat-bottomed 96-well plate filled with $200 \mu \mathrm{L}$ of the medium (TSB with $2 \%$ glucose). Sub-MIC concentrations of thymol were added $(200,100,75$, and $50 \mu \mathrm{g} / \mathrm{mL})$ and each concentration was added to at least three wells. After biofilm growth, the content of each well was removed and the plate was washed and stained with crystal violet and re-dissolved as already described for evaluation of biofilm formation. The OD was measured at a wavelength of $600 \mathrm{~nm}$ using 
a plate reader (GloMax ${ }^{\circledR}$-Multi Detection System). The experiments were run at least in triplicates and three independent experiments were performed. To calculate the percentages of inhibition the following formula was used:

$$
\% \text { of Inhibition }=\frac{O D \text { growth control }-O D \text { sample }}{O D \text { growth control }} \times 100 \% .
$$

The calculation of mean and SD was done on a PC with the computer program, Microsoft Excel 2010.

\subsection{Anti-Biofilm Activity}

The medium from each well of the 24-h-old biofilm was removed and the plate was washed and left to dry. Aliquots of $200 \mu \mathrm{L}$ of fresh medium (TSB with $2 \%$ glucose) were added to each well followed by aliquots of thymol to reach concentrations equal to MIC and $2 \times$ MIC obtained against the planktonic forms of the tested strains. The microtiter plate was sealed with parafilm and incubated at $37^{\circ} \mathrm{C}$ for $24 \mathrm{~h}$. The content of each well was removed and the plate was washed twice with $0.9 \%$ sterile $\mathrm{NaCl}(200 \mu \mathrm{L}$ to each well) and left to dry. The staining procedure was performed as described above. The OD was measured at a wavelength of $600 \mathrm{~nm}$ using the plate reader (GloMax ${ }^{\circledR}$-Multi Detection System). The experiments were run at least in triplicates and three independent experiments were performed. The percentages of inhibition can be calculated with Equation (1) as described above.

\subsection{Inhibition of Biofilm Formation on Circular Stainless-Steel Coupons Using the Viable Plate Count Method}

In a 24-well plate, circular sterile stainless-steel coupons (14-15 mm diameter with $1.0 \mathrm{~mm}$ thickness) were put as the flat-bottom in each well. Each well was filled with $2 \mathrm{~mL}$ of TSB with $2 \%$ glucose and a sub-MIC concentration $(100 \mu \mathrm{g} / \mathrm{mL})$ of thymol was added. An aliquot of $25 \mu \mathrm{L}$ from a suspension of L. monocytogenes LM 101 with OD of about 0.040 at $570 \mathrm{~nm}$, corresponding to approximately $10^{6} \mathrm{CFU} / \mathrm{mL}$, was added to each well. After incubation for $24 \mathrm{~h}$, the content of each well was removed and the bottom surface was washed twice with $0.9 \%$ sterile $\mathrm{NaCl}(2 \mathrm{~mL}$ to each well). The inoculum scraped from the stainless-steel surface was put in a test tube with $10 \mathrm{~mL}$ of $\mathrm{NaCl}(0.9 \% w / v$ solution) and sonicated (ultrasonic nominal power equal to $215 \mathrm{kHz}$ ) for $2 \mathrm{~min}$. A suitable number of 10 -fold dilutions were prepared and $100 \mu \mathrm{L}$ aliquots of each dilution were plated in TSA [31]. Plates were then incubated at $37^{\circ} \mathrm{C}$ and $\mathrm{CFU} / \mathrm{mL}$ were counted after $24 \mathrm{~h}$ and compared to $\mathrm{CFU} / \mathrm{mL}$ formed on growth control wells without inhibitor and growth control wells with $2 \% v / v$ ethanol used to dissolve thymol. All tests involved two replicates and were repeated at least in three independent experiments. The activity was reported in terms of log reduction of viable plate counts [24]. The calculation of mean and SD was done on a PC with the computer program, Microsoft Excel 2010.

\subsection{Statistical Analysis}

Data were analyzed using the Bartlett's test for homogeneity of variances and analysis of variance (ANOVA). Means were statistically separated on the basis of Student-Newman-Keuls test, when the F-test of ANOVA for treatment was significant at least at the 0.05 probability [23].

Author Contributions: Project conceptualization, D.S. and M.V.; antimicrobial and anti-biofilm investigation, M.G.C.; molecular biology investigation, M.L.G.; data curation, F.P.; writing—original draft preparation, V.D.S. and M.V.; writing-review and editing, D.S.; funding acquisition, V.D.M.L.P. and M.V. All authors have read and agreed to the published version of the manuscript.

Funding: This research was funded by Ministero della Salute (Italy) IZSSI08/16RC and IZS13/15RC grants to MV.

Acknowledgments: We gratefully acknowledge the Italian Reference Laboratory for Listeria monocytogenes (IRL), Istituto Zooprofilattico Sperimentale of Abruzzo and Molise, Teramo, Italy.

Conflicts of Interest: The authors declare no conflict of interest. 


\section{References}

1. Jasovský, D.; Littmann, J.; Zorzet, A.; Cars, O. Antimicrobial resistance-A threat to the world's sustainable development. Ups. J. Med. Sci. 2016, 121, 159-164. [CrossRef] [PubMed]

2. Woolhouse, M.; Ward, M.; van Bunnik, B.; Farrar, J. Antimicrobial resistance in humans, livestock and the wider environment. Philos. Trans. R. Soc. Lond. B Biol. Sci. 2015, 370, 20140083. [CrossRef] [PubMed]

3. Manyi-Loh, C.; Mamphweli, S.; Meyer, E.; Okoh, A. Antibiotic Use in Agriculture and Its Consequential Resistance in Environmental Sources: Potential Public Health Implications. Molecules 2018, 23, 795. [CrossRef] [PubMed]

4. Martens, E.; Demain, A.L. The antibiotic resistance crisis, with a focus on the United States. J. Antibiot. 2017, 70, 520-526. [CrossRef] [PubMed]

5. Liu, Q.; Meng, X.; Li, Y.; Zhao, C.-N.; Tang, G.-Y.; Li, H.-B. Antibacterial and Antifungal Activities of Spices. Int. J. Mol. Sci. 2017, 18, 1283. [CrossRef]

6. Hall, C.W.; Mah, T.-F. Molecular mechanisms of biofilm-based antibiotic resistance and tolerance in pathogenic bacteria. FEMS Microbiol. Rev. 2017, 41, 276-301. [CrossRef]

7. Schillaci, D.; Spanò, V.; Parrino, B.; Carbone, A.; Montalbano, A.; Barraja, P.; Diana, P.; Cirrincione, G.; Cascioferro, S. Pharmaceutical Approaches to Target Antibiotic Resistance Mechanisms. J. Med. Chem. 2017, 60, 8268-8297. [CrossRef]

8. Djordjevic, D.; Wiedmann, M.; McLandsborough, L.A. Microtiter plate assay for assessment of Listeria monocytogenes biofilm formation. Appl. Environ. Microbiol. 2002, 68, 2950-2958. [CrossRef]

9. Kurpas, M.; Wieczorek, K.; Osek, J. Ready-to-eat Meat Products as a Source of Listeria monocytogenes. J. Vet. Res. 2018, 62, 49-55. [CrossRef]

10. Sandasi, M.; Leonard, C.; Viljoen, A. The effect of five common essential oil components on Listeria monocytogenes biofilms. Food Control 2008, 19, 1070-1075. [CrossRef]

11. Geraci, A.; Di Stefano, V.; Di Martino, E.; Schillaci, D.; Schicchi, R. Essential oil components of orange peels and antimicrobial activity. Nat. Prod. Res. 2017, 31, 653-659. [CrossRef] [PubMed]

12. Nyila, M.A.; Leonard, C.M.; Hussein, A.A.; Lall, N. Activity of South African medicinal plants against Listeria monocytogenes biofilms, and isolation of active compounds from Acacia karroo. S. Afr. J. Bot. 2012, 78, 220-227. [CrossRef]

13. Ferreira, S.; Domingues, F. The antimicrobial action of resveratrol against Listeria monocytogenes in food-based models and its antibiofilm properties. J. Sci. Food Agric. 2016, 96, 4531-4535. [CrossRef] [PubMed]

14. Nostro, A.; Sudano Roccaro, A.; Bisignano, G.; Marino, A.; Cannatelli, M.A.; Pizzimenti, F.C.; Cioni, P.L.; Procopio, F.; Blanco, A.R. Effects of oregano, carvacrol and thymol on Staphylococcus aureus and Staphylococcus epidermidis biofilms. J. Med. Microbiol. 2007, 56, 519-523. [CrossRef] [PubMed]

15. Braga, P.C.; Culici, M.; Alfieri, M.; Dal Sasso, M. Thymol inhibits Candida albicans biofilm formation and mature biofilm. Int. J. Antimicrob. Agents 2008, 31, 472-477. [CrossRef] [PubMed]

16. Buchanan, R.L.; Gorris, L.G.M.; Hayman, M.M.; Jackson, T.C.; Whiting, R.C. A review of Listeria monocytogenes: An update on outbreaks, virulence, dose-response, ecology, and risk assessments. Food Control 2017, 75, 1-13. [CrossRef]

17. Yair, Y.; Gophna, U. Pandemic Bacteremic Escherichia coli Strains: Evolution and Emergence of Drug-Resistant Pathogens. Curr. Top. Microbiol. Immunol. 2018, 416, 163-180.

18. Kerekes, E.-B.; Vidács, A.; Török, J.J.; Gömöri, C.; Petkovits, T.; Chandrasekaran, M.; Kadaikunnan, S.; Alharbi, N.S.; Vágvölgyi, C.; Krisch, J. Anti-listerial effect of selected essential oils and thymol. Acta Biol. Hung. 2016, 67, 333-343. [CrossRef]

19. Liu, Q.; Niu, H.; Zhang, W.; Mu, H.; Sun, C.; Duan, J. Synergy among thymol, eugenol, berberine, cinnamaldehyde and streptomycin against planktonic and biofilm-associated food-borne pathogens. Lett. Appl. Microbiol. 2015, 60, 421-430. [CrossRef]

20. Orhan-Yanıkan, E.; da Silva-Janeiro, S.; Ruiz-Rico, M.; Jiménez-Belenguer, A.I.; Ayhan, K.; Barat, J.M. Essential oils compounds as antimicrobial and antibiofilm agents against strains present in the meat industry. Food Control 2019, 101, 29-38. [CrossRef] 
21. Hebbelstrup Jensen, B.; Poulsen, A.; Hebbelstrup Rye Rasmussen, S.; Struve, C.; Engberg, J.H.; Friis-Møller, A.; Boisen, N.; Jønsson, R.; Petersen, R.F.; Petersen, A.M.; et al. Genetic Virulence Profile of Enteroaggregative Escherichia coli Strains Isolated from Danish Children with Either Acute or Persistent Diarrhea. Front. Cell. Infect. Microbiol. 2017, 7, 230. [CrossRef] [PubMed]

22. Chakraborty, A.; Saralaya, V.; Adhikari, P.; Shenoy, S.; Baliga, S.; Hegde, A. Characterization of Escherichia coli Phylogenetic Groups Associated with Extraintestinal Infections in South Indian Population. Ann. Med. Health Sci. Res. 2015, 5, 241-246.

23. Snedecor, G.W.; Cochran, W.G. Statistical Methods, 8th ed.; Iowa State University Press: Ames, IA, USA, 1989.

24. Galié, S.; García-Gutiérrez, C.; Miguélez, E.M.; Villar, C.J.; Lombó, F. Biofilms in the Food Industry: Health Aspects and Control Methods. Front. Microbiol. 2018, 9, 898. [CrossRef] [PubMed]

25. Nazzaro, F.; Fratianni, F.; De Martino, L.; Coppola, R.; De Feo, V. Effect of Essential Oils on Pathogenic Bacteria. Pharmaceuticals 2013, 6, 1451-1474. [CrossRef] [PubMed]

26. Mahizan, N.A.; Yang, S.-K.; Moo, C.-L.; Song, A.A.-L.; Chong, C.-M.; Chong, C.-W.; Abushelaibi, A.; Lim, S.-H.E.; Lai, K.-S. Terpene Derivatives as a Potential Agent against Antimicrobial Resistance (AMR) Pathogens. Molecules 2019, 24, 2631. [CrossRef] [PubMed]

27. Kim, J.; Jeon, S.; Rhie, H.; Lee, B.; Park, M.; Lee, H.; Lee, J.; Kim, S. Rapid Detection of Extended Spectrum $\beta$-Lactamase (ESBL) for Enterobacteriaceae by use of a Multiplex PCR-based Method. Infect. Chemother. 2009, 41, 181-184. [CrossRef]

28. Bai, J.; Paddock, Z.D.; Shi, X.; Li, S.; An, B.; Nagaraja, T.G. Applicability of a multiplex PCR to detect the seven major Shiga toxin-producing Escherichia coli based on genes that code for serogroup-specific O-antigens and major virulence factors in cattle feces. Foodborne Pathog. Dis. 2012, 9, 541-548. [CrossRef]

29. Clermont, O.; Christenson, J.K.; Denamur, E.; Gordon, D.M. The Clermont Escherichia coli phylo-typing method revisited: Improvement of specificity and detection of new phylo-groups. Environ. Microbiol. Rep. 2013, 5, 58-65. [CrossRef]

30. Schillaci, D.; Spinello, A.; Cusimano, M.G.; Cascioferro, S.; Barone, G.; Vitale, M.; Arizza, V. A peptide from human $\beta$ thymosin as a platform for the development of new anti-biofilm agents for Staphylococcus spp. and Pseudomonas aeruginosa. World J. Microbiol. Biotechnol. 2016, 32, 124. [CrossRef]

31. Schillaci, D.; Petruso, S.; Raimondi, M.V.; Cusimano, M.G.; Cascioferro, S.; Scalisi, M.; La Giglia, M.A.; Vitale, M. Pyrrolomycins as potential anti-staphylococcal biofilms agents. Biofouling 2010, 26, 433-438. [CrossRef]

Sample Availability: Sample of the compound thymol is available from the authors.

(C) 2020 by the authors. Licensee MDPI, Basel, Switzerland. This article is an open access article distributed under the terms and conditions of the Creative Commons Attribution (CC BY) license (http://creativecommons.org/licenses/by/4.0/). 